SERIE DE DOCUMENTOS DE TRABAJO FEIPU

ISSNe: 2745-2085

\title{
El abecé de la beligerancia y su aplicabilidad con el ELN. Génesis y desafíos inmediatos
}

\author{
Lina María Mejía Torres \\ Mauricio Jaramillo Jassir
}


El abecé de la beligerancia y su aplicabilidad con el ELN: génesis y desafíos inmediatos / Lina María Mejía Torres, Mauricio Jaramillo Jassir. -- Bogotá: Universidad del Rosario. Facultad de Estudios Internacionales, Políticos y Urbanos, 2020.

39 páginas. -- (Documentos de Trabajo FEIPU; 1)

Incluye referencias bibliográficas.

ISSNe: $2745-2085$

Doi: https://doi.org/10.12804/issne.2745-2085_10336.31360_sddtf

1. Ejército de Liberación Nacional -- Colombia. 2. Beligerancia -- Colombia. 3. Conflicto armado -- Colombia. 4. Combatientes y no combatientes (Derecho Internacional). I. Mejía Torres, Lina María. II. Jaramillo Jassir, Mauricio. III. Universidad del Rosario, Facultad de Estudios Internacionales, Políticos y Urbanos. IV. Título. V. Serie.

341.6 SCDD 20

Catalogación en la fuente -- Universidad del Rosario. CRAI

DJGR mayo 03 de 2021 


\title{
El abecé de la beligerancia y su aplicabilidad con el ELN. Génesis y desafíos inmediatos
}

\author{
Lina María Mejía Torres \\ Mauricio Jaramillo Jassir
}

\author{
Universidad del Rosario \\ Facultad de Estudios Internacionales, Políticos y Urbanos \\ Editorial Universidad del Rosario \\ Bogotá, D.C. \\ Mayo de 2021
}


Lina María Mejía Torres

Mauricio Jaramillo Jassir

Editorial Universidad del Rosario

Facultad de Estudios Internacionales, Políticos y Urbanos

ISSN: 2745-2085

Doi: https://doi.org/10.12804/issne.2745-2085_10336.31360_sddtf

Ella Suárez

Corrección de estilo

Fredy Johan Espitia Balleteros

Diagramación

* Las opiniones de los Artículos sólo comprometen a los autores y en ningún caso a la Universidad del Rosario. No se permite la reproducción total ni parcial sin la autorización de los autores.

Todos los derechos reservados

Primera edición: mayo de 2021

Hecho en Colombia

Made in Colombia 


\section{Contenido}

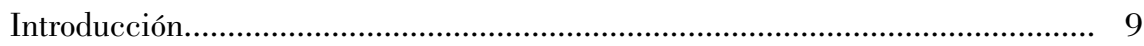

1. Ubicación de la beligerancia en el derecho ............................................... 12

2. Conflictos armados ¡internacionalizados? ............................................... 20

3. Colombia y su proceso interrumpido de internacionalización ......................... 25

4. Génesis y actualidad de la beligerancia del ELN .......................................... 30

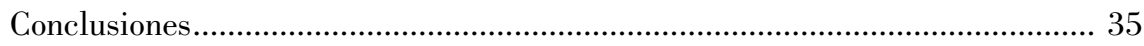

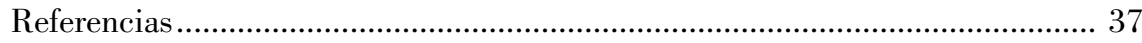





\title{
El abecé de la beligerancia y su aplicabilidad con el ELN. Génesis y desafíos inmediatos ${ }^{*}$
}

\author{
Basics on Belligerence Status and its Application to the National \\ Liberation Army. Origins and Immediate Challenges
}

\author{
Lina María Mejía Torres \\ Mauricio Jaramillo Jassir ${ }^{* \star}$
}

\section{Resumen}

El estatus de beligerancia es una de las nociones más evocadas en el último tiempo, cuando se contemplan formas para humanizar el conflicto armado colombiano. Sin embargo, a pesar de que exista un sumario desarrollo jurídico al respecto, no se tiene certeza de sus implicaciones reales y los prejuicios sobre su eventual aplicación impiden cualquier discusión equilibrada acerca de su viabilidad. El presente texto tiene como propósito esclarecer el panorama

\footnotetext{
El contenido de las ideas expresadas en este documento es responsabilidad exclusiva de los autores y no ha sido sometido a ningún proceso de revisión por pares.

** Abogada. Magíster (LL. M.) en Derechos Humanos y Derecho Internacional Humanitario de American University Washington College of Law. Consultora en Derechos Humanos y Derecho Internacional Humanitario. Profesora de la Maestría en Defensa de los Derechos Humanos de la Universidad Santo Tomás. Correo electrónico: linamejiat@gmail.com

*** Profesor de la Facultad de Estudios Internacionales, Políticos y Urbanos de la Universidad del Rosario. Doctor en Ciencia Política de la Universidad de Toulouse. Máster en Geopolítica de la Universidad París 8 y Relaciones Internacionales de SciencesPo Toulouse e Internacionalista del Rosario. Correo electrónico: mauricio.jaramilloj@urosario.edu.co
} 
sobre la beligerancia y su aplicabilidad respecto del estatus del ELN, tomando en consideración no solo la lógica jurídica, indispensable en su compresión y concreción, sino a la luz de su uso en otros casos que, aun cuando diferenciables del conflicto colombiano, comparten la internacionalización como proceso, a la vez que como mecanismo para la humanización. Así, se trata de aclarar su contenido y alcance para estimular una discusión que sobrepase los sesgos con los que se aborda. El documento consta de cuatro partes: la ubicación de la beligerancia en el derecho internacional humanitario, el análisis de la noción conflicto internacionalizado, la internacionalización en el caso colombiano y, finalmente, la aplicabilidad de dicho estatus para el ELN.

Palabras clave: beligerancia; conflicto internacionalizado; conflicto armado.

\section{Abstract}

Belligerence is one of the most controversial notions when it comes to the internal armed conflict in Colombia. Although there is a substantial support from the international humanitarian law, there is not enough knowledge about its limits and implications. The purpose of this document is to highlight belligerence status feasibility in Colombia taking into consideration: the most recent international law advances that are essential to its comprehension and other cases of armed conflicts in which belligerence status has been important. Our main purpose is to explore belligerence avoiding the biased readings that have prevailed in Colombia in the last years, that is why we approach the subject according to four parts: belligerence's definition and development; internationalized conflict's concept analysis; Colombian conflict internationalization process; and finally, belligerence status feasibility regarding the National Liberation Army.

Keywords: Belligerence; internationalized armed conflict; armed conflict. 


\section{Introducción}

La década de 1990 significó un drástico recrudecimiento del conflicto armado en Colombia, observable en homicidios, desapariciones forzadas, amenazas y múltiples secuestros. En 1999, en medio de la trágica situación, el expresidente colombiano Alfonso López Michelsen propuso el reconocimiento de una "beligerancia restringida" para las Fuerzas Armadas Revolucionarias de Colombia (FARC) como una fórmula con doble propósito: liberar a los retenidos y lograr un proceso de paz que pusiera fin a décadas de enfrentamientos. Desde ese momento, el país comenzó a debatir sobre la posibilidad de lograr dicha liberación a través de un acuerdo humanitario.

La propuesta — que en ese entonces provocó controversia y fue rechazada por buena parte de la dirigencia colombiana- fue reveladora en cuanto a los prejuicios que, aun hoy en día, suscita la figura. Una de las razones por las cuales se ha desestimado no consiste tanto en su viabilidad jurídica o inaplicabilidad, como en el hecho de ser equivocadamente interpretada como una conquista político-militar de las guerrillas y, subsecuentemente, una derrota irreparable para el Estado.

Constitucionalistas, politólogos, militares retirados y políticos han reflexionado en torno a la cuestión, casi siempre en el formato de columnas de opinión, como en el caso de Juan Manuel Charry (19 de enero de 2008), Eduardo Pizarro Leongómez (9 de mayo de 2011), Jaime Castro (23 de agosto de 2012), Alfredo Rangel (18 de junio de 1995) y el general Álvaro Valencia Tovar (23 de junio de 1995 y 22 de octubre de 1999). Sobresale como una obra relevante de López Michelsen (2008), Cómo desempantanar el acuerdo humanitario y otros escritos sobre el conflicto armado y la humanización de la guerra, con prólogo de Ernesto Samper Pizano, otro pionero de la discusión.

Una de estas reflexiones provino de Alfredo Rangel (1995), a mediados de los años noventa, cuando la humanización del conflicto estaba en etapa embrionaria. El analista consideraba que la beligerancia era uno de los caminos hacia la humanización que "hace parte de los temas tabú [... no obstante] otorgarles ese estatus no sería perjudicial [...] sino conveniente para el esclarecimiento, la regularización y la humanización del conflicto, lo cual nos podría poner en la vía de su solución". En la otra orilla, militares y varios académicos del 
sector defensa se han opuesto, por considerarla una innecesaria concesión, además de ser lesiva para los intereses del Estado colombiano. El general Valencia Tovar fue el crítico más inmediato de las primeras reflexiones de López Michelsen, Rangel y Samper, pues para él significaba equiparar injustamente la jerarquía de las guerrillas a la del Estado, cuando era evidente el "deslizamiento hacia estados y conductas simplemente delincuenciales" (1995). La beligerancia, descrita por Rangel como un mecanismo legal para la humanización, era considerada por el general en retiro como la posibilidad inminente de "eternizar la guerra" (Valencia Tovar, 1999).

A partir de ese entonces, no ha dejado de ser un tema examinado en formatos de opinión. Empero, textos académicos o de mayor extensión son más bien excepcionales, y aunque exista una literatura voluminosa sobre la humanización de conflictos armados de carácter no internacional, parecen más bien escasos los referentes sobre la beligerancia y sobre conflictos internacionalizados desde Colombia.

Aun así, la beligerancia ha constituido uno de los temas más complejos, polémicos e invocados a lo largo del conflicto armado colombiano. Desde que en la década de 1990 el Estado emprendiera la interiorización de las normas del derecho internacional humanitario (DIH) ha estado presente la inquietud acerca de sus límites y alcances respecto de las guerrillas. ¿Es posible afirmar que cuando el Estado negocia con estos grupos les otorga estatus político? ¿Aquello los convierte en sujetos de legalidad, con lo cual contraen derechos y deberes? ¿De qué forma se puede garantizar respeto por las normas del DIH por parte de actores no estatales? Preguntas que parecen anacrónicas y trasnochadas; pero que conservan intacta su pertinencia y relevancia.

Recientemente, tras la firma de los Acuerdos de La Habana con las FARC, quedó de manifiesto la importancia del reconocimiento de terceros Estados para darle viabilidad al proceso, transparencia a las decisiones parciales y un esquema de verificación permanente. Este último aspecto ha sido clave cuando la desconfianza entre las partes abunda por antecedentes que dan cuenta de violaciones sistemáticas a lo acordado.

En medio de este debate enquistado en las lógicas del conflicto y poco abordado desde la academia, este texto de discusión busca servir de insumo, al demostrar que el reconocimiento de la beligerancia es un mecanismo útil no solo para la humanización — proceso urgente que limita los daños de la guerra-, sino que puede servir como camino hacia una negociación que sea 
del todo viable con el Ejército de Liberación Nacional (ELN). Teniendo en cuenta que la internacionalización constituye una tendencia comprobable y sostenida en Colombia, es posible apoyarse en el DiH para sobrepasar aquellas lógicas que ven en la humanización una estrategia con miras a conseguir ventajas político-militares y entender que el reconocimiento del carácter político del ELN no constituye una legitimación de sus acciones y, menos aún, avalar dicha violencia. Desde la segunda mitad del siglo Xx, son varios los procesos de paz aleccionadores respecto de la manera en que el derecho, la negociación y la participación de actores internacionales son esenciales para que se remuevan las causas objetivas que conducen a la violencia. En sentido inverso, la misma evidencia empírica sugiere que cuando se combate o evita el conflicto por medio exclusivamente de la deslegitimación del adversario, negando su carácter político y simplificándolo como delincuente, se reduce de forma significativa la violencia en el corto plazo, pero tiende a reaparecer con incluso más fuerza.

Para lograr este propósito, el documento se divide en cuatro partes. En primer lugar, se aborda el panorama de la beligerancia según el DiH, tratando de esclarecer su origen, desarrollo y vigencia jurídica actual. Aunque se trate de una figura cuya interpretación da pie para una aplicación flexible, es preciso reconocer y entender cómo se ubica dentro del mapa del derecho. En segundo lugar, se analiza la categoría conflicto armado internacionalizado, de James Stewart (2003), que advierte sobre las dificultades para la aplicación del DIH en conflictos internos y la manera como una internacionalización con determinados matices puede facilitar su desactivación. Para ello se apela a los casos paradigmáticos de El Salvador y Palestina. En tercer lugar, se describe la internacionalización del conflicto colombiano, proceso deliberado y presente en todos los gobiernos desde los años noventa, sin excepción. Aquello permite una lectura del involucramiento de actores internacionales en distintas fases y con diferentes objetivos según el contexto. Finalmente, se explica el proceso por medio del cual el ELN ha venido accediendo a un estatus político y beligerante, a pesar de que no se haya concretado de forma expresa. Lo anterior debe conducir a una discusión reposada, alejada de la excesiva ideologización con la que se suele simplificar la paz en Colombia y con miras a aclarar los alcances y limitaciones de la beligerancia, mecanismo subestimado que merece una lectura renovada frente a su aplicación para humanizar el conflicto armado. 


\section{Ubicación de la beligerancia en el derecho}

El reconocimiento de la beligerancia se ha entendido como la posibilidad de que un grupo armado sea reconocido bajo las normas aplicables como un sujeto de derecho internacional y, por tanto, con capacidad similar o equivalente a los Estados para combatir en un conflicto armado en igualdad de condiciones, con derechos y garantías.

Como uno de los antecedentes puntuales, las convenciones de La Haya de 1899 y de 1907 establecieron algunas características que deben detentar los grupos armados para ser catalogados como beligerantes. La Convención de 1899 determinó que deben cumplir condiciones mínimas de composición y el trato debido a los prisioneros de guerra; la Convención de 1907 precisó que los beligerantes debían asumir las acciones cometidas por integrantes del grupo armado y aplicar la Convención de 1899.

Por otro lado, es importante aclarar que al recurrir al contenido del artículo 3 común, la existencia de un conflicto armado se determina por factores objetivos y subsiste independiente de la denominación de los Estados, grupos armados o partes del conflicto; esto quiere decir que el hecho de caracterizar el conflicto no tiene, en principio, influencia en el estatus político o jurídico de las partes.

En 1900 el Instituto de Derecho Internacional consignó las pautas para reconocer qué se entiende por beligerante y definió que: “i) El grupo debe de tener organización y mando, en el sentido que opere bajo un esquema de autoridad jerárquica en que se reconozca una cadena de mando y unas autoridades responsables por las acciones del grupo", y "ii) [el] grupo debe controlar por lo menos una porción de territorio del Estado donde tiene lugar el conflicto". A pesar de que no lo indique expresamente, se ha desarrollado en la doctrina y la jurisprudencia internacional que el control debe ser tanto permanente como público y haber sido logrado por las armas. Como último elemento, la resolución del Instituto destaca que "iii) el grupo debe respetar lo que se suele llamar las leyes y los usos de la guerra" (Quintana, 2001).

Los Convenios de Ginebra (i, ii y iii) señalan a los integrantes de grupos beligerantes dentro de su regulación y aplican su contenido para proteger a las víctimas de los conflictos armados. Es importante destacar qué se entiende 
por grupo armado. Según el Protocolo II de los Convenios de Ginebra de 1949 se debe cumplir con lo siguiente: i) ser un grupo armado organizado, ii) estar bajo la dirección de un mando responsable, iii) ejercer sobre una parte de dicho territorio un control tal, que iv) le permita realizar operaciones militares sostenidas y concertadas y v) aplicar el Protocolo.

El artículo 1 del Protocolo II dispone que los conflictos armados se podrán desarrollar en el territorio de una alta parte contratante entre sus fuerzas armadas y disidentes o grupos armados organizados. De allí se sustrae, igualmente, que el contenido del Protocolo es de forzosa aplicación para quienes se encuentren en casus belli ${ }^{1}$ dentro del territorio; esto incluye a todos los grupos armados de cualquier naturaleza (incluso los que no estén reconocidos como insurrectos) salvo los grupos de "delincuencia común". ${ }^{2}$

El Protocolo II y el artículo 3 común tienen una finalidad exclusivamente humanitaria; por consiguiente, se aclaró que su aplicación no constituía un reconocimiento del estado de beligerancia o una modificación de la naturaleza jurídica entre las partes del conflicto.

No obstante, el Comentario del Protocolo II pone de presente que la declaración o reconocimiento del estado de beligerancia puede llevar a que se trate de un acto jurídico unilateral, de carácter discrecional, que puede adoptar una forma expresa o tácita, siendo esta última aquella "que engloba la mayoría de los casos, se deduce de medidas o de una actitud del Gobierno ante una situación conflictiva interna (por ejemplo, un bloqueo)" (Comité Internacional de la Cruz Roja [CICR], 2008).

En esta línea, el acto de reconocimiento da origen a una nueva situación jurídica y responde a un estado que hace aplicable entre el "Gobierno y los insurrectos" todo el derecho de los conflictos armados. Así es como el reconocimiento es una manifestación de la competencia del Estado que no desconoce la soberanía nacional para hacer la guerra y, por tanto, se indica que "se limita a conferir a los insurrectos cierta personalidad jurídica, como sujetos de derechos y obligaciones, dentro de los límites del derecho de la guerra" (CICR, 2008).

$1 \quad$ El casus belli se refiere a un evento o acción que justifica una guerra o conflicto.

2 La doctrina y la jurisprudencia han señalado que existe una diferencia entre reconocimiento de beligerancia y de insurgencia, que fue una práctica en Estados Unidos reservada para un grupo se secesionistas que no dominaba un territorio; pero que "se haga a la mar", con el fin de evitar que los rebeldes puedan ser tratados como piratas. La práctica fue admitida en el Fallo del Tribunal del Distrito de Nueva York en el asunto Abrose Light de 1885. 
Expuestos los elementos generales de la beligerancia, es necesario ampliar su desarrollo, contenido y alcance frente a la capacidad de aplicar el reconocimiento de aquella a situaciones particulares de conflictos armados, en especial la capacidad de conferir dicho estatus.

En este aspecto, los registros de negociación para el Protocolo Adicional II revelan que algunos Estados afirmaron que la aplicabilidad de este instrumento a los actores armados no estatales les confiere un estatus de beligerante, así como los criterios para la aplicabilidad del Protocolo equivalen a las condiciones necesarias para dicho reconocimiento. Sin embargo, bajo las diferentes interpretaciones de estos requisitos, se ha señalado que si bien la beligerancia requiere una "administración ordenada", esta característica no es indispensable en el Protocolo Adicional II.

Asimismo, el alcance del control territorial puede llegar a ser diferente, pues se requiere que en una parte del territorio se puedan llevar a cabo operaciones militares e implementar el Protocolo, lo que bajo la doctrina de la beligerancia se ha determinado como la ocupación de una parte sustancial del territorio. El control territorial, sin embargo, puede corresponder a una pequeña parte, lo que podría ser suficiente para llevar a cabo operaciones militares y, en consecuencia, aplicar las previsiones del Protocolo y satisfacer un criterio relevante para otorgar el reconocimiento.

El desarrollo doctrinal y la práctica del DiH han demostrado que persisten disensos frente a la aplicación del reconocimiento de beligerancia tanto en conflictos armados internacionales como en no internacionales. Buena parte del contenido del reconocimiento de la beligerancia está incluido en el derecho internacional consuetudinario, y los criterios de implementación, según cada contexto, pueden variar entre expreso, tácito o incluso verbal; sin embargo, la práctica estatal muestra que existen excepciones frente a la disposición de reconocer la beligerancia como un acto de política exterior y desdeñar su verdadera utilidad en el marco de la humanización de los conflictos armados.

En el ámbito jurisprudencial se han constituido elementos clave para interpretar la beligerancia, como en el caso Prosecutor vs. Tadic n. ${ }^{\circ}$ IT-94-1-T, Appeals Chamber, del Tribunal para la Antigua Yugoslavia, que declaró la existencia de reglas consuetudinarias de derecho internacional como posibilidad para determinar la responsabilidad penal individual acorde a la capacidad de su aplicación y que analizó la práctica de la beligerancia por parte de autoridades nacionales en el marco del DIH y sus cláusulas de protección. 
En la decisión, el párrafo 96 se refiere a las reglas consuetudinarias retomando la dicotomía de la respuesta legal basada en la violencia armada en la comunidad internacional y su implicación en las actuaciones de las partes en conflicto, la cual tiene como sustento la beligerancia versus la insurgencia. Se recuerda que esta primera categoría era aplicada a los conflictos armados entre Estados soberanos, y la segunda, a la violencia armada dentro de su territorio. Así, el derecho internacional abordó dos clases de conflicto: las guerras interestatales reguladas en sus hostilidades por un conjunto de normas internacionales y la protección de las personas que no participaban o habían dejado de hacerlo en el conflicto.

A contrario sensu, las reglas internacionales que regulan la conmoción interna o civil no eran claras o eran mínimas, por lo que los Estados optaron por una interpretación de la lucha interna como rebelión, motín o traición y sustrajeron su ámbito de aplicación del derecho penal nacional. ${ }^{3}$ Esta lógica asociada a la soberanía responde a la configuración tradicional de la comunidad internacional, basada en la coexistencia de Estados que velaban por sus intereses más allá de la comunidad, cooperación o, incluso, necesidades humanitarias.

En la decisión señalada, en el párrafo 106, se establecen, de igual forma, las tendencias de autoridades nacionales frente al reconocimiento de la beligerancia que tiene como referencia inicial la Guerra Civil española, donde no se le reconoce, pero se extiende la aplicación de las normas legales sobre conflictos. Adicionalmente, se explica que en el Código de Conducta Operacional para las Fuerzas Armadas de Nigeria (regulación de la conducción de las operaciones militares del Gobierno federal) "para reprimir la rebelión en Biafra, las tropas federales tenían el deber de respetar las reglas de los Convenios de Ginebra y, además, cumplir con un conjunto de reglas que protegen a los civiles y objetos civiles en el teatro de operaciones militares" (Kirk-Greene, 1971). Además, indica que en algún punto se negó el reconocimiento de beligerancia y se consideró aplicar no solo las disposiciones de los Convenios de Ginebra, sino las normas sobre la conducción de hostilidades generalmente aplicables en conflictos internacionales. ${ }^{4}$

3 Esto, además, trajo como consecuencia excluir la intrusión de otros Estados en su jurisdicción interna.

4 La sentencia aclara que "esta actitud de las autoridades nigerianas confirma la tendencia iniciada con la Guerra Civil española [...] según la cual las autoridades centrales de un Estado en el que ha estallado la lucha civil prefieren negar el reconocimiento de la beligerancia, pero al mismo tiempo, extender al conflicto la aplicación del mayor parte del conjunto de normas legales sobre los conflictos entre Estados" (Kirk-Greene, 1971). 
En Opinion and Judgement del caso Prosecutor vs. Tadic n. ${ }^{\circ}$ IT-94-1-T, en el Tribunal para la Antigua Yugoslavia se discierne acerca de la aplicación de la beligerancia. ${ }^{5}$ Se determina que la protección que puede reclamar la población civil bajo el derecho internacional consuetudinario se basa en "la aplicación continua a favor del estándar de civilización en todos los asuntos en los que esto no va en contra de las necesidades de la guerra. Las disposiciones del Convenio IV de Ginebra de 1949 que no se limitan a los territorios ocupados se suman a este mínimo de protección" (International Criminal Tribunal for the former Yugoslavia, 1997).

Por su parte, el Tribunal Penal Internacional para Ruanda aborda la perspectiva del conflicto armado no internacional, específicamente en el caso Prosecutor vs. Akayesu ICTR-96-4-T, en los párrafos 619 y 620, que señalan que se debe reconocer a los beligerantes y enuncia que el artículo 3 común a los Convenios de Ginebra puede ser aplicable para distinguir conflictos armados genuinos de meros actos insurgentes no organizados. Igualmente, precisa algunos elementos frente a la beligerancia, al establecer que "la Parte en rebelión contra el Gobierno de jure posee una fuerza militar organizada, una autoridad responsable de sus actos, que actúa dentro de un territorio determinado y que tiene los medios para respetar y garantizar el respeto de la Convención" (International Criminal Tribunal for Rwanda, 1998). Además, establece como criterios de referencia alguno de los siguientes: i) el Gobierno de jure ha reconocido a los insurgentes como beligerantes, ii) ha reclamado para sí los derechos de beligerantes, iii) ha otorgado a los insurgentes reconocimiento como beligerantes a los efectos de la Convención y iv) que la disputa ha sido admitida en la agenda del Consejo de Seguridad o de la Asamblea General de las Naciones Unidas como una amenaza a la paz internacional, una violación de la paz o un acto de agresión. ${ }^{6}$

En el ámbito de lo doctrinal, es posible identificar que esta percepción recae particularmente en los actores armados no estatales y aun cuando el reconocimiento de beligerancia en el marco de la firma de un acuerdo de paz carece en la práctica de varios criterios, puede constituir una capacidad

5 El análisis se enfoca hacia el control efectivo de territorios, sin embargo, su dimensión se extrae para entender el ámbito del reconocimiento y su impacto en las víctimas del conflicto armado.

6 De la práctica se concluye: aunque los Estados nieguen cualquier reconocimiento de beligerancia, puede ocurrir por parte de terceros. Así mismo, acuerdos de actores no estatales con Estados contra los que están luchando son una forma de reconocimiento de beligerancia y, en algún sentido, los convierte en sujetos de derecho internacional. 
correspondiente a un sujeto de derecho internacional, máxime cuando "el acuerdo de paz, aunque se rompe en algún momento, se presenta como un válido documento con el fin efectivo del conflicto armado" (Pacheco Sánchez, 2013).

No obstante, en la doctrina internacional existen desacuerdos frente a la posibilidad de declarar que los grupos son solo sujetos de DIH, pero no de derecho internacional; por tanto, con personalidad jurídica limitada y sin capacidad para celebrar pactos internacionales. Sin embargo, según la doctrina del ius contrahendi, algunos grupos armados organizados, estables y con control territorial tienen personalidad jurídica internacional para celebrar acuerdos internacionales con efectos vinculantes. ${ }^{7}$

Esta revisión general de la beligerancia, de acuerdo con el derecho internacional y el DIH, permite entender que se trata de una aplicación condicionada que varía según cada conflicto. Como resulta obvio, el caso colombiano puede estudiarse a partir del momento en que la posibilidad de beligerancia asoma en medio de la internacionalización, proceso determinante que, como se verá, arroja luces sobre la viabilidad o imposibilidad de aplicar normas humanitarias en el conflicto.

Para 1991 se debatía en Colombia sobre el "impacto" de suscribir el Protocolo II de los Convenios de Ginebra, especialmente desde la beligerancia regulada por el Convenio de La Haya que se podría conceder; no obstante, surgía el impulso para suscribir el Protocolo con el objetivo de que los actores del conflicto conocieran y reconocieran materialmente las afectaciones a la población civil producto del enfrentamiento armado. ${ }^{8}$

Como referencia expresa, los Convenios de Ginebra señalaban a los integrantes de los grupos beligerantes dentro de la regulación para proteger a las víctimas de los conflictos armados, y bajo este escenario "los Convenios fueron aprobados por la Ley 5 de 1960". En este sentido, los antecedentes verifican que en estos debates no se presentaba un fundamento estructural mediante el cual se argumentara expresamente que el reconocimiento del conflicto y de los instrumentos que lo pretendían limitar correspondieran

7 Algunos autores como Alston, Sassòli, Bouvier, Quintin, Waschefort, Sandesh Sivakumaran o Bell han planteado que, incluso, estos actores gozan de personalidad jurídica internacional concedida por el DIH.

8 En el trámite de ratificación se indicó también que adoptar los instrumentos de DIH no requería otorgar un estatus a la organización beligerante; pero en cambio sí obligaba a exigir el respeto por su contenido hacia la población civil. Se advierte que, finalmente, en la postura de debate no existía un consenso general al respecto; solo lo hubo hasta el momento de su ratificación. 
automáticamente al otorgamiento de algún estatus político. ${ }^{9}$ En definitiva, la Ley 171 de 1994 aprobó el contenido del Protocolo II, lo que tuvo especial valor para la regulación del conflicto armado interno desde un enfoque de protección a la población civil.

En relación con los elementos de reconocimiento de beligerancia a grupos armados, se ha aludido a que no existe una referencia consumada mediante la cual se den por satisfechos los requisitos para ello; es claro que sus fundamentos indican organización y mando o control territorial, pero el requisito “esencial" frente a esto recae, en principio, en la aceptación o en la aplicación del DIH, bien sea en su actuar o en sus estatutos. De ahí que se pueda evaluar su respeto para otorgar la beligerancia.

Se debe insistir en que la principal consecuencia del reconocimiento por parte del Gobierno es que los beligerantes estén obligados a respetar las leyes de guerra vigentes. La doctrina establece que el reconocimiento transforma el carácter voluntario de la "observancia de las leyes de la guerra por parte de los insurgentes a una obligación de ambas partes en el conflicto" (CICR, 1984). De hecho, en el derecho consuetudinario ${ }^{10}$ se ha planteado que las actividades bélicas de los insurgentes no serán consideradas actos de violencia sin ley, que en ausencia de reconocimiento podría someterlos a otro tratamiento.

Teniendo en cuenta esta previsión, se incluyen incluso los deberes y derechos que son aplicables durante la guerra y las reglas de responsabilidad internacional. ${ }^{11}$ Bajo esta lógica, la Resolución 10 estableció algunos de sus alcances, pues advirtió que las condiciones bajo las cuales una parte en "conflicto puede ser reconocido como beligerante por las potencias que no participan en este conflicto se rigen por las normas generales del derecho internacional sobre el tema" (CICR, 2012). Además, el artículo 3.4 común contiene una cláusula abierta que puede significar que, aunque la aplicación de su contenido no confiere expresamente un estado beligerante, deja abierta la opción para ese reconocimiento en determinados casos. De igual modo,

9 Sin embargo, se hace la salvedad de que el contenido de dichos convenios efectivamente comprendía el elemento de beligerancia.

10 La ley pertinente para la guerra marítima y las actividades bélicas de los insurgentes, especialmente en alta mar.

11 En términos del reconocimiento, así mismo, se ha incluido que esta acepción puede ser extendida a los derechos humanos, pues el beligerante podría configurarse como una entidad con un límite y personalidad jurídica internacional provisional que incurre en ciertos deberes y derechos bajo el derecho internacional consuetudinario. 
el artículo 2.3 común abre la oportunidad a los beligerantes para aplicar los Convenios de Ginebra.

Bajo estos términos, se deben analizar las aristas que comportan las salidas negociadas al conflicto, el reconocimiento o involucramiento de terceros y los referentes de procesos internacionales aplicables al caso colombiano. 


\section{Conflictos armados ¿internacionalizados?}

La internacionalización del conflicto colombiano ha sido uno de los procesos más visibles en los últimos tiempos. Esta se define como el involucramiento de actores internacionales en algunas de las fases del conflicto, bien sea para liberaciones de carácter humanitario; para la verificación de un cese al fuego o un desescalamiento; para la evacuación de heridos; para el acompañamiento, facilitación o mediación en las negociaciones; o para una observación general del proceso de cumplimiento de acuerdos; entre otros. Se trata de apoyarse en actores de la comunidad internacional por medio de instituciones internacionales o Estados, para avanzar en su resolución.

Hasta la década de los noventa, resultaba impensable esta internacionalización para el caso colombiano. De acuerdo con Rodrigo Pardo y Leonardo Carvajal (2003), los militares que estuvieron al mando del ministerio hasta 1990 se oponían, pues presumían que la internacionalización implicaba de forma automática el reconocimiento de beligerancia para las guerrillas. De igual forma, en plena Guerra Fría se pensaba que cualquier aceptación del conflicto armado frente a la comunidad internacional podía allanar el camino para una intervención de las potencias en disputa. Tal como le recuerda Sandra Borda (2007), el proceso no siempre ocurre de forma deliberada y otros actores, terceros Estados o instituciones, pueden empujar o estimular el proceso de forma tal que, es difícil pensar en un gobierno que controle de forma absoluta la internacionalización.

Ahora bien, es importante diferenciar internacionalización de regionalización del conflicto, nociones que en el caso colombiano han tendido a ser equiparadas. La segunda no implica un proceso deliberado, sino la expansión cada vez más frecuente de las operaciones armadas más allá de las fronteras de un Estado, en el escenario típico de insurgentes que utilizan territorios periféricos y fronterizos como santuarios. Habida cuenta de las dificultades para controlarlos por razones geográficas, históricas e incluso vinculadas a la cultura política (en el caso de Colombia el marcado centralismo), el conflicto tiende a la regionalización. En esa misma lógica, también se debe señalar que ni la internacionalización ni la regionalización implican que el conflicto adquiera una naturaleza internacional. 
James Stewart propone la categoría conflictos armados internacionalizados para aquellos que tienen elementos internos e internacionales y retoma varias de las críticas que consideran que los criterios para diferenciar conflictos internos de internacionales podrían ser "arbitrarias, no deseables o difícilmente justificables" (Dupuy \& Leonetti; Detter; Warbrick \& Rowe citados en Stewart, 2003, p. 313).

En esa misma línea argumentativa, José Manuel Sánchez Patrón recuerda que "Tan solo un reducido número de normas [...] se aplican a los conflictos armados internos" (Sánchez Patrón, 2006, p. 64). Aquello constituye un desafío mayor teniendo en cuenta que, desde la segunda mitad del siglo xx, la mayor parte ocurre dentro de los Estados, aunque con una marcada regionalización e internacionalización. Como una prueba más de la relevancia de los conflictos internos se debe mencionar que, finalizando la década de los noventa, investigar las causas y los procesos vinculados a las llamadas guerras internas se convirtió en un objetivo central del estudio de las Relaciones Internacionales (David, 1997). Con ello, varias disciplinas convergieron en el análisis de la violencia, por lo que su estudio se complejizó y se pudo contrastar con acceso a un volumen de datos inéditos que derivó en comparaciones en el pasado impensables. Por ende, Stewart propone:

[...] un derecho unificado para los conflictos armados que se justifica por la actual imposibilidad de que el actual régimen humanitario se aplique en conflictos que contienen elementos internacionales y no-internacionales y considerados como internacionalizados. [...]

El término "conflictos armados internacionalizados" describe hostilidades internas que se convierten en internacionales. Las circunstancias de facto que configuran dicha internacionalización son numerosas y frecuentemente complejas. (2003, pp. 314 y 315$)$

Y evoca como ejemplos claros de estos conflictos algunos de los más catastróficos desde el punto de vista humanitario, ocurridos a lo largo de la década de los noventa: la desintegración de Yugoslavia, la guerra posterior a raíz de Kosovo y el conflicto en la República Democrática del Congo con matices regionales significativos. Como consecuencia evidente de la Guerra Fría, cita el caso de la injerencia de Estados Unidos con los contras en Nicaragua a comienzos de la década de 1980 (Stewart, 2003). 
Estas últimas definiciones de conflictos internacionalizados dejan dudas sobre su aplicabilidad en Colombia, pues no existe claridad de que un tercer Estado haya tomado partido. Terceros Estados e instituciones internacionales han intervenido en las facilitaciones, los buenos oficiales o verificación, pero preservando la imparcialidad. Ahora bien, ¿el apoyo militar de Estados Unidos o el reconocimiento político de algunos vecinos al estatus político de las guerrillas implica de alguna manera un apoyo para considerarlo un conflicto internacionalizado? La respuesta parecería negativa, debido a que Washington solo reconoce un bando; por tanto, a su entender no está tomando parte en una guerra, y el reconocimiento de terceros a la guerrilla ocurre por pedido del Estado colombiano.

Estos planteamientos deben ser contrastados a la luz de evidencia empírica; para ello, es prudente observar los casos del conflicto palestino-israelí y la guerra civil salvadoreña, cuya internacionalización fue clave para poner en marcha un proceso de negociación viable.

En el caso palestino, luego de que pasara de ser una guerra árabe-israelí, para centrarse enteramente en la disputa entre palestinos e israelíes se observa un claro proceso de internacionalización, tratándose de uno de los más referenciados por encima incluso de la desintegración de Yugoslavia o el de los Grandes Lagos en el África Subsahariana. En 1964, nació la Organización de la Liberación de Palestina (OLP), que fue difundiendo la causa nacional con la intención de establecerse como Estado y lograr el retorno de los refugiados que se fueron acumulando a lo largo de las guerras de 1948, 1967 y 1973. En ese sentido, fue importante el reconocimiento, en 1974, de la Asamblea General de Naciones Unidas de la olP como vocera de ese pueblo, hito que marcó el involucramiento de la sociedad internacional en una eventual resolución del conflicto. El primer gran reto que enfrentaron las Naciones Unidas respecto del conflicto palestino-israelí (superadas las confrontaciones armadas entre Estados árabes y Tel Aviv) ocurrió con la primera intifada o levantamiento de los palestinos en los Territorios Ocupados, en 1987. La trayectoria de la oLP le permitía tener una vocería para que cuando Europa y Estados Unidos propusieran una negociación, hubiese dos partes sentadas a la mesa y se lograra detener la violencia. A esta serie de acuerdos firmados a lo largo de los años noventa se les denominó Acuerdos de Oslo, ${ }^{12}$ y aunque no derivaron en

12 Fueron iniciativa de una organización no gubernamental noruega, aunque jamás se firmó alguno en ese territorio. 
una paz duradera, ni concretaron el ideal de dos Estados, se mantienen como el principal referente de una eventual negociación en el futuro.

El reconocimiento de beligerancia no supuso de ninguna forma contemplación con lo que pudiese ser considerado actos de terrorismo. Este caso también es excepcional, pues la internacionalización sí modificó la naturaleza del conflicto. La reivindicación palestina de ser un Estado la convirtió en un actor internacional, de suerte que el conflicto pasó a tener dos actores internacionalmente reconocidos, aunque la condición estatal de Palestina sea fácilmente puesta en entredicho, pues carece del control de las fronteras y del monopolio legítimo de la fuerza.

En el caso salvadoreño convergen los procesos de regionalización e internacionalización. El primero se explica por la manera en que se le fue considerando de manera arbitraria como una extensión del conflicto bipolar entre Moscú y Washington, en especial por el segundo, que tenía un vivo interés por contener cualquier movimiento o partido político que pudiese alinearse con los soviéticos. El triunfo de la Revolución Sandinista en Nicaragua, a finales de la década de 1970, provocó una agresiva reacción hasta que los conflictos en América Central empezaron a traspasar sus fronteras y la injerencia de terceros fue evidente, al punto de observarse los matices de las definiciones de regionalización e internacionalización descritas. En 1981, cuando empezaba la estrategia de apoyo a los contras por parte de Estados Unidos en Nicaragua, en El Salvador, Francia y México optaron por sumar esfuerzos y reconocer el estatus de beligerancia del Frente Democrático Revolucionario y el Frente Farabundo Martí para la Liberación Nacional (FDR-FMLN). Ambos gobiernos admitieron que se trataba de una "fuerza representativa" que debía tener la opción de negociar y convertirse en sujeto de derecho. Se instó a la "Comunidad Internacional para que, dentro del marco de las Naciones Unidas, se asegurara la protección de la población civil, de acuerdo con las normas aplicables, y se facilitara el acercamiento entre los representantes de las fuerzas políticas salvadoreñas" (Embajada de Francia, 2016).

Lejos de tomar partido por el FDR-FMLN, la Declaración partió del supuesto comprobable de que el conflicto tenía sus orígenes en las limitaciones a la participación de varios sectores que hacían imposible una democratización plena (Torres Rivas, 2002). Si el origen del conflicto era meramente político, la solución debía atender esa lógica. 
Esa declaración se transformó en un hito diplomático que allanó el camino de la paz y luego, con el apoyo del Grupo de Contadora, se confirmaron los esfuerzos regionales que lograron una paz que tuvo como punto de llegada reformas al sistema democrático de los centroamericanos. ${ }^{13}$

13 A comienzos de la década de 1980 se conformó el Grupo de Contadora, que contó con la presencia de Colombia, México, Venezuela y Panamá, y cuyo fin era promover la paz en América Central, insistiendo en la no injerencia para llegar a acuerdos de largo aliento. 


\section{Colombia y su proceso interrumpido de internacionalización}

A inicios de la década de 1990, comenzaron los intentos de negociación entre las diferentes guerrillas colombianas y el Estado con una activa participación de Cuba, México y Venezuela, que lograron avances sustanciales, a pesar de que no se llegó a una paz definitiva. Esos esquemas de diálogo deben entenderse como un antecedente para la concreción de los Acuerdos de La Habana, veinticinco años después.

A mediados de los años noventa, se produjo el avance más representativo, en términos de una internacionalización humanitaria, durante el mandato de Ernesto Samper Pizano. Colombia firmó y ratificó el Protocolo Adicional a los Convenios de Ginebra de 1977 sobre Conflictos Armados de Carácter no Internacional. A su vez, se acordó con el secretario general de las Naciones Unidas la instalación de una oficina permanente del Alto Comisionado para los Derechos Humanos y se concretaron acuerdos con el CICR para facilitar su labor en medio del conflicto. Por recomendación de la Comisión Interamericana de Derechos Humanos, ese Gobierno fue el primero en la historia en reconocer la responsabilidad del Estado en la Masacre de Trujillo, una serie de asesinatos ocurridos a finales de los años ochenta y comienzos de los noventa en el Valle del Cauca. Samper no solo expresó una disculpa pública, sino que conformó una Comisión de la Verdad que terminó siendo pionera en el complejo proceso de reconstrucción de la memoria histórica (Pardo \& Carvajal, 2003).

Como se verá más adelante, este Gobierno intentó un diálogo con el ELN en Mainz (Alemania); pero resultó infructuoso. Con estos antecedentes, quedaba claro que no sería posible una negociación sin el factor internacional, esencial para la facilitación, el acompañamiento y la verificación de los acuerdos parciales que se fueran logrando.

Con la promesa de la paz, Andrés Pastrana ganó las elecciones de 1998 y, de inmediato, desplegó una serie de esfuerzos para establecer un grupo de países amigos de la paz para una negociación con las FARc. Este se llevó a cabo en una zona desmilitarizada en el sur de Colombia. En virtud de ese esquema, Canadá, Cuba, España, Francia, Italia, México, Noruega, Suecia, Suiza y Venezuela conformaron la llamada Comisión de Facilitación. Posteriormente, 
se sumó un enviado especial del secretario general de las Naciones Unidas, James Lemoyne. Este conjunto fue clave en momentos de tensión entre Gobierno y guerrilla, cuando el proceso parecería irremediablemente fracasar por desacuerdos y acusaciones mutuas ("Los diez países amigos regresan”, 2002).

Inicialmente, Estados Unidos apoyó la negociación, como resultado de un contacto entre Andrés Pastrana y Bill Clinton, incluso antes de la posesión del primero, y en el que el estadounidense habría expresado un apoyo al diálogo. Antes de tomar posesión, Pastrana ya había concertado una visita de miembros del Departamento de Estado a Colombia para terminar de afinar el apoyo de Washington al posconflicto colombiano.

El proyecto de Pastrana para el involucramiento de actores internacionales bajo el eslogan "internacionalizar la paz para terminar la guerra" comportaba dos dimensiones: la Comisión Facilitadora y la participación de la comunidad internacional para financiar una parte representativa del posconflicto colombiano. Pastrana partía del supuesto lógico de que la reconstrucción, luego de décadas de conflicto, requeriría una ingente inversión de recursos. Se refería a tal proyecto como un Plan Marshall para Colombia, en el que "no se trata[ba] solo de la cooperación para lo concerniente a la negociación y a velar por el cumplimiento de los acuerdos, sino también de la participación decidida en la estructuración, financiación y ejecución de un ambicioso proyecto de largo plazo" (Pastrana, 1999, p. 55).

En este plan de reconstrucción se contaba inicialmente con el apoyo de Estados Unidos, la Unión Europea y Japón. Sin embargo, la coyuntura cambió drásticamente cuando apenas transcurridos algunos meses de dicha administración, en noviembre de 1998, las FARC llegaron a controlar, por primera vez, la capital de un departamento, Mitú. La toma guerrillera ocurrió precisamente cuando miembros del Departamento de Estado, Peter Romero y Philip Chicola, se reunían en Bogotá con Jaime Ruiz, director del Departamento Nacional de Planeación; Rodrigo Lloreda Caicedo, ministro de Defensa, y el propio Pastrana. Romero, impactado por la toma de Mitú, habría pactado con Pastrana modificar el plan de reconstrucción en el posconflicto para fortalecer el Estado colombiano, especialmente la Fuerza Pública, que parecía la urgencia más inmediata. De este modo, se gestó una estrategia militar por pedido del Gobierno colombiano, y Peter Romero se convirtió en un importante aliado, pues accedió a los apoyos del lado del Gobierno estadounidense (Méndez, 2017). De allí emergió la tesis de Arlene Tickner sobre la "intervención por 
invitación" (2007, p. 90), en la que se describe cómo la participación de Washington no ha sido necesariamente una imposición.

Como agravante mayor, en febrero de 1999, las FARC asesinaron a tres antropólogos estadounidenses (Terence Freitas, Ingrid Washinawatok y Laheenae Gay), con lo cual Washington retiró cualquier apoyo al proceso de paz con esa guerrilla. No obstante, Estados Unidos terminó siendo un actor fundamental en la internacionalización del conflicto colombiano durante el gobierno de Andrés Pastrana y, desde ese entonces, mantiene un papel variante.

Con Álvaro Uribe Vélez la internacionalización fue un proceso inconstante. En principio, buscó el apoyo del secretario general de las Naciones Unidas, Kofi Annan, para que ejerciera sus buenos oficios con las FARC; pero la guerrilla descartó cualquier posibilidad de diálogo con ese Gobierno, que anteponía como condición un alto al fuego:

El papel de la onv en otros conflictos ha sido cuestionado. En Ruanda, en Indonesia, en los Balcanes, hoy en el Medio Oriente con el drama del pueblo palestino. Recientemente este órgano mundial absolvió al Estado de Israel por la masacre de Jenín [...] Ahora bien, pueden ofrecer el Papa o la reina Isabel de Gran Bretaña sus buenos oficios, pero si no hay una voluntad de cambio del Establecimiento colombiano se cierra la posibilidad de ponerle fin a la confrontación armada. ("Las FARC desestiman la mediación de la onU", 2002)

El último tramo del Gobierno de Pastrana había significado la antesala de la estrategia de internacionalización de Uribe. En febrero de 2002, tras romper el diálogo con las FARC por el secuestro del congresista Jorge Géchem Turbay, el Gobierno anunció la retoma militar de la zona despejada y lanzó una ofensiva diplomática para cerrar los espacios internacionales a la guerrilla. Por consiguiente, y aprovechando la Presidencia en México de Vicente Fox, del Partido de Acción Nacional (pan), alejado los principios de política exterior del Partido Revolucionario Institucional (PRI) ${ }^{14}$ se solicitó la expulsión

14 Durante la hegemonía del PRI, México acogió a quienes se consideraban perseguidos políticos, por lo que, durante la segunda mitad del siglo xx, recibió un sinnúmero de personas que allí encontraron refugio. Además, guardó siempre buenas relaciones con Cuba, al ser el primer gobierno de la región en reconocer su carácter socialista y, desde ese entonces, se convirtió en el país que más insistió en denunciar las sanciones económicas decretadas por Estados Unidos. La llegada del Pan en 2000 supuso un cambio radical en esa materia, que condujo a un distanciamiento con Cuba. Por primera vez, México votó por una propuesta de Uruguay para mejorar la situación de los derechos humanos en la isla, en la entonces Comisión de Derechos Humanos de Naciones Unidas en Ginebra. 
de "Marcos Calarcá", con lo que la guerrilla perdió un espacio de difusión. Luego, tanto Estados Unidos como la Unión Europea pasaron a considerar a las FARC como organización terrorista.

Ante la negativa de esa guerrilla a negociar y poniendo siempre como condición inamovible un despeje militar, Uribe procedió a una ofensiva militar sin antecedentes que produjo resultados, al tiempo que la guerra se recrudecía. Luego de una reelección histórica y apoyado con índices de aprobación superlativos, Uribe llegó a la mitad de su segundo mandato con un bemol inocultable: las condiciones de los secuestrados por la guerrilla hacían aumentar la presión de la sociedad civil por lograr un acuerdo humanitario o un canje de prisioneros según el léxico de las FARC.

De forma sorpresiva, Bogotá propuso a Caracas como facilitadora en los acercamientos que condujeran a la liberación de secuestrados, como fase previa a un eventual proceso de negociación. Con esa gestión, se logró la liberación de Clara Rojas, Consuelo Gonzales, Gloria Polanco y Jorge Géchem, entre otros. El papel del cicr fue esencial para otorgar garantías y puso al descubierto la importancia de terceros actores en la concreción de acciones humanitarias, especialmente cuando existe una marcada desconfianza entre los bandos. En ese contexto, el Gobierno venezolano, que había liderado varios escenarios regionales, propuso otorgar el reconocimiento de beligerancia a las FARC, algo que generó rechazo por parte del Gobierno colombiano y algunos sectores que veían en tal pedido una muestra de simpatía ideológica hacia la guerrilla. No obstante, Chávez argumentaba que era la mejor forma de comprometerla a abandonar la práctica del secuestro $\mathrm{y}$ respeto por las normas del DIH.

Es probable que la FARC hubiesen entendido que la beligerancia otorgaba condiciones favorables para una negociación con garantías, cuya ausencia en el pasado hacía inviable los procesos de paz en Colombia. De acuerdo con Eduardo Pizarro Leongómez (2011), las FARC tenían tres grandes proyectos a comienzos de siglo: la toma de Bogotá a través del tránsito de la guerra de guerrillas a una de posiciones, con el apoyo de frentes y de compañías móviles; una campaña internacional para el reconocimiento de beligerancia aprovechando la disposición del Gobierno de Venezuela, y un proceso de diálogo con el entonces Gobierno de Pastrana, que — de acuerdo con Pizarro Leongómez- no se contemplaba verdaderamente. Ahora bien, es necesario matizar la idea de Pizarro Leongómez para entender que aquello no suponía una alianza entre las 
FARC y Caracas. La disposición venezolana se puede rastrear incluso antes de la llegada de Chávez, cuando algunos gobiernos subnacionales venezolanos, especialmente los fronterizos, habían mostrado voluntad para negociar con esa guerrilla, para que no atacara civiles venezolanos.

No obstante, ni el pedido expreso de Chávez a las FARC para abandonar el secuestro ni su propuesta para el reconocimiento como fuerza beligerante bastaron para que la idea tomara fuerza y otros países se sumaran, de forma tal que fuese posible una aplicación cabal de normas humanitarias. Posteriormente, Uribe dio por terminada la facilitación venezolana, acusando a Chávez de injerencia, cuando el venezolano se comunicó con el comandante del Ejército, Mario Montoya, solicitando información acerca de operaciones militares en una zona donde había un cese al fuego.

Finalmente, en el gobierno de Juan Manuel Santos, la internacionalización fue clave para darle legitimidad y viabilidad a la negociación con las FARC y el ELN, aunque con este último no se concretara un acuerdo final. Con la primera, Noruega sirvió como un territorio neutral para establecer los primeros acercamientos, y una vez acordada la agenda, se pactó el acompañamiento de Chile, Cuba y Venezuela.

El escenario presentado marca la trayectoria de Colombia en diferentes espacios de negociación y la manera en que los factores internacionales, desde la década de 1990, han estado presentes de forma ininterrumpida, bien fuera para la facilitación, para el acompañamiento o para la verificación. 


\section{Génesis y actualidad de la beligerancia del ELN}

Existe evidencia de aproximaciones en las que el ELN reconoció el DIH en una clara manifestación de su disposición para mantener un comportamiento humanitario con la población civil. A través de plenos, conferencias y planes, como se verá más adelante, dicho reconocimiento se fue haciendo más expreso, por lo que se plantearon posteriormente procesos de paz, acuerdos sobre el DIH y escenarios de solución política con el objeto de humanizar el conflicto.

En el II Pleno de la Dirección Nacional, la UC-ELN “Darío Ramírez Cardona y Héroes", entre junio y julio de 1988, propuso un cese temporal condicionado que abarcaba el sabotaje a oleoductos. Posteriormente, propuso un "Convenio por la Vida", para lograr un acuerdo para humanizar la guerra, incluyendo el respeto a los Convenios de Ginebra.

En esta propuesta se ratificó la existencia de un conflicto armado interno y señaló que el Gobierno no estaba aplicando el DIH y planteó dos aspectos fundamentales para humanizar la guerra: i) "La intermediación del Comité de la Cruz Roja Internacional para adelantar un Convenio por la humanización de la guerra entre el gobierno colombiano y las fuerzas insurgentes; tratamiento debido a la población civil y tratamiento debido a los prisioneros de guerra" (Galán \& Torres, 1995) y ii) "Acompañar la propuesta de un conjunto de exigencia al gobierno colombiano, consistentes en: respeto a la población civil, a sus vidas, que cesaran los bombardeos, los saqueos y el desalojo en las zonas de conflicto [... $]^{15}$ (Galán \& Torres, 1995)".

Así mismo, el Plan Nacional de la Organización, en 1989, consagró que la organización debía desarrollar la actividad política, militar y de masas bajo los ejes de vida y soberanía. En 1990, como parte de las conclusiones del II Congreso, en forma del anexo "concepciones para una nueva propuesta", se planteó la posibilidad de concretar ceses de acciones militares, establecer

15 Además, disponía que se respetara a la vida de los luchadores populares y de los dirigentes de las organizaciones políticas y gremiales; que cesaran las torturas, desapariciones y asesinatos de combatientes capturados; que se desmantelara la estructura de los grupos paramilitares y se adelantaran juicios sumarios contra sus participantes intelectuales y materiales. 
el manejo y control de armamentos como minas y bombas y acordar criterios básicos de relaciones contra la población civil involucrada en la guerra. En el III Congreso, el ELN formuló la implementación del derecho y el juzgamiento de los delitos "que atenten contra la sociedad y sean los cimientos de la nueva Constitución" (Medina, 2012).

En mayo de 1991, en el Gobierno de César Gaviria, se llegó al Acuerdo de Cravo Norte con la Coordinadora Guerrillera Simón Bolívar (CGSB) y se establecieron conversaciones directas en Caracas y el compromiso de las medidas relacionadas con la seguridad y el traslado de los comisionados de la Coordinadora Guerrillera al lugar elegido para las conversaciones. Así empezó la internacionalización que incluyó al ELN. Con Samper Pizano, en julio de 1998, se suscribió el Acuerdo de Puerta del Cielo, en el que se preveía un proceso de paz con la participación sostenida de la sociedad civil. En el aspecto humanitario, se condenaron las acciones hostiles y las masacres de civiles; se excluyeron de ataques armados a los "activos" o bienes protegidos por el DiH; así como se aceptaron las recomendaciones para el trato humano de las personas retenidas, los homicidios planeados y ejecuciones arbitrarias de no combatientes, el uso de minas que afectaran a civiles, la investigación de responsabilidades por abusos cometidos por la guerrilla, el respeto de los derechos de los niños y la promoción para ratificar la Convención de Ottawa sobre la proscripción de minas.

Durante el III Congreso, en 1996, el ELN planteó de nuevo la posibilidad del diálogo y la negociación para el fin del conflicto y, dos años más tarde, en Mainz, como se hizo alusión, se suscribió un compromiso para humanizar la guerra. En este se habló de iniciar un proceso de paz, garantizando la participación de la sociedad civil y con acompañamiento de la comunidad internacional.

Ahora bien, para esta época y en periodos ulteriores, los supuestos bajo los cuales se podría efectuar un reconocimiento a la beligerancia se configuraban principalmente bajo uno de los requisitos más importantes: la regulación por medio del DIH. Se destaca, así, el deseo expreso del ELN por lograr la humanización del conflicto haciendo referencia al Protocolo II, para que fuera un elemento jurídico rector de las partes a través de la propuesta "El Convenio por la vida", que requería la aplicación del derecho internacional y de las normas internacionales de la guerra.

Durante el Gobierno de Pastrana, la mayor parte de las negociaciones se encaminó a la liberación de secuestrados. En junio de 1999 se produjo un encuentro entre una Comisión Humanitaria del Gobierno y el ELn, con el 
objeto de gestionar la liberación de los secuestrados de un vuelo comercial desde Bucaramanga a Bogotá y durante la celebración de un oficio religioso en la iglesia La María de Cali. La comisión de trabajo dispuso los arreglos para la seguridad del área, la presencia internacional, los recursos logísticos y las actividades humanitarias para lograr dicha liberación. El 30 de octubre de 2000, Gobierno y ELN acordaron los términos para la liberación de civiles retenidos y se reanudaron las conversaciones en torno al proceso de paz y la posibilidad de llegar a un acuerdo sobre el DIH.

El 24 de noviembre de 2001, acordaron reiniciar el diálogo con una Agenda de Transición, ${ }^{16}$ que preveía foros temáticos y entre ellos, el DIH (Peace Agreements, 2001). A pesar de esto, las conversaciones sufrieron un serio revés, por cuenta de la campaña "Bolívar", ofensiva en lugares cercanos a la zona de negociaciones, y el Comando Central del ELn suspendió así indefinidamente los diálogos. Después, en el Gobierno de Uribe Vélez se priorizó la pacificación por la vía militar y se incluyó a esa guerrilla en las listas internacionales de organizaciones terroristas, lo que terminó por cerrar los espacios de negociación.

Aun así, en 2004, a través del documento El destino de Colombia, una responsabilidad colectiva (Comando Central del ELn, 2004), el Comando Central convocó a un encuentro para retomar los diálogos, y ese mismo año propuso un acuerdo humanitario para construir escenarios de solución política del conflicto armado y la reactivación de un proceso de negociación sobre la base de i) limitación sobre el uso de minas y artefactos explosivos, ii) amnistía y iii) cese al fuego bilateral y temporal.

Durante el Gobierno de Juan Manuel Santos, y cuando abundaban las expectativas por lo logrado con las FARC, se suscribió un acuerdo con el ELN para un diálogo de paz (30 de marzo de 2016). ${ }^{17}$ Frente a las disposiciones humanitarias, los puntos de la agenda contemplaban, entre otras, dinámicas y acciones humanitarias, cese al fuego bilateral y fin de hostilidades para la terminación del conflicto armado. Un año después, ocurrió un hito fundamental en la internacionalización del proceso con el ELN (24 de septiembre de 2017), pues se registró la aplicación al Consejo de Seguridad sobre la Participación de las Naciones Unidas en la Verificación y aplicación del Cese Bilateral, Temporal y Nacional,

16 El Acuerdo proscribe la voluntad de encontrar una solución política al conflicto y reiniciar el proceso de diálogo mediante una agenda de fortalecimiento de la paz como política de Estado.

17 Con los siguientes puntos de agenda: 1) participación de la sociedad civil en la búsqueda de paz, 
mediante el cual se concretó un Mecanismo de Verificación e Implementación, responsable de verificar el cumplimiento de tal cese.

En términos humanitarios, más allá de los acuerdos, también se identifica que las disposiciones de este tipo han sido vinculadas a los mismos estatutos y normas de comportamiento de los actores armados. Específicamente, el ELN en las "Normas de Comportamiento con las Masas (CGSB)" se comprometió a:

1. [...] respetar las ideas y actitudes políticas, filosóficas y religiosas de la población; 2. tener en cuenta la seguridad de trabajadores en los planes de trabajo político militar; 3. privilegiar que se evite que la gente inocente y/o amiga quede a merced de los terrorismos y del odio; 4. considerar un delito el asesinato y toda clase de atropellos que se comprueben cometidos contra la población; y, 5. investigar los reclamos de la comunidad sobre agresiones de combatientes.

Merecen especial atención los puntos 11 y 13, donde se dispone que "Los mandos y combatientes deben estudiar y practicar las normas del DIH acordes a las condiciones de nuestra guerra revolucionaria" (Coordinadora Guerrillera Simón Bolívar, s.f.).

No obstante, los últimos acuerdos suscritos con el ELN en 2016 y 2017 se deben analizar a la luz del DiH y las normas y costumbres de los conflictos armados. En este sentido, producto de la mesa de diálogos, se establecieron previsiones de aplicación tanto en relación con el conflicto como con las negociaciones políticas que rodearon dicho proceso. Para el particular, se pactaron acuerdos respecto a la capacidad bélica (Punto 5. Fin del conflicto armado) e incluso un Protocolo de ruptura (firmado adicionalmente el 5 de abril de 2016). En esta medida, la referencia específica a la aplicación del marco del DIH se mantuvo en el acuerdo de 2016 en el punto 5.f: "dinámicas y acciones humanitarias", con el objeto de proteger a la población civil y las personas no combatientes de los efectos del conflicto armado.

Es importante señalar que las partes y los países garantes (Cuba, Chile, Noruega y Venezuela) de la mesa de diálogo firmaron un documento para establecer los lineamientos y las garantías de seguridad de la delegación del ELN en caso de ruptura de las negociaciones. Entre 2017 y 2018, producto de los diálogos de paz, se estableció un Cese al Fuego Bilateral Monitoreado por las Naciones Unidas y se acordó adelantar un programa piloto de desminado, la observancia de los requerimientos humanitarios (caso Chocó y litoral pacífico) y el trabajo sobre aspectos de contención humanitaria y cese 
al fuego ampliado. Bajo este último punto, Gobierno y guerrilla solicitaron a las Naciones Unidas participar en calidad de componente internacional y coordinador en un mecanismo de monitoreo y verificación, a fin de seguir su cumplimiento. La Resolución 281 de 2017 del Consejo de Seguridad de las Naciones Unidas respaldó la declaración del cese al fuego, con el propósito de aliviar la situación humanitaria. ${ }^{18}$

Los antecedentes expuestos del ELN constituyen actos que pueden implicar el reconocimiento de la beligerancia en sentido tácito y que como último fin vislumbra condicionamientos humanitarios para el conflicto. Se establece, así, que los contenidos de las diferentes actuaciones estudiadas pueden constituir un reconocimiento parcial o incluso restringido concretado mediante actos unilaterales del Estado, como aquellos de 2016 o 2017. Los fundamentos mediante los cuales se puede apreciar su aplicación se derivan de los elementos recabados en el primer y segundo aparte de este documento y que explican la beligerancia, el sentido de su reconocimiento y su utilidad en el marco de la humanización de los conflictos armados.

18 La Resolución en concreto estableció que la Misión de Verificación de las Naciones Unidas — previamente establecida en Colombia mediante la Resolución 2366 de 2017- participara en el mecanismo de monitoreo y verificación y coordinara labores, a fin de 1) verificar el cumplimiento del alto el fuego bilateral, temporal y nacional con el ELN en los ámbitos nacional, regional y local, y 2) prevenir incidentes mediante la coordinación estrecha de las partes y la solución de desacuerdos. 


\section{Conclusiones}

En la doctrina, la jurisprudencia y la evidencia empírica convergen fundamentos para concluir que el ELN ha tenido un estatus político y, de manera parcial y tácita, cierto reconocimiento de beligerancia que, de todos modos, debería perfeccionarse.

De igual forma, es posible plantear una personalidad jurídica internacional limitada para adquirir obligaciones, especialmente de un actor armado para entrar en negociaciones en el mismo equilibrio o condiciones de un Estado, como se observa en varios de los elementos recabados y que explican, desde varias ópticas, la beligerancia y el sentido de su reconocimiento.

La internacionalización humanitaria se ha evidenciado en el apoyo, gestión, facilitación, acompañamiento y verificación por parte de terceros, con una efectividad comprobada en la negociación con las FARC, y que podría representar una salida negociada con el ELN y, de paso, aclarar, de una vez por todas, que ese reconocimiento beligerante no significa una victoria militar, sino la materialización de condiciones favorables para negociar con garantías históricamente ausentes.

Por otra parte, a través de los fundamentos, como la lex pacificatoria, se han definido diversas vías jurídicas para regular los procesos de paz y su impacto frente a la práctica de los actores armados, teniendo en cuenta el derecho internacional. En este contexto, han surgido nuevas expresiones que intentan dar sentido a los esfuerzos para la búsqueda de la paz; de este modo, se aplicó la pacigerancia, que puede considerarse como salida o aplicación viable. Así, se entiende que tanto el ius ad bellum ${ }^{19}$ como el ius in bellum ${ }^{20}$ sustentan la beligerancia y que el ius post bellum la fundamentan y conceden a un grupo insurgente mediante una personalidad jurídica para negociar y firmar la paz.

19 El ius ad bellum se refiere a las condiciones bajo las cuales los Estados pueden recurrir a la guerra o al uso de la fuerza armada en general.

20 El ius in bellum regula la conducta de las partes involucradas en un conflicto armado. El ius in bellum se ha utilizado como sinónimo del DiH, porque busca minimizar el sufrimiento en los conflictos armados, especialmente para proteger y ayudar a las víctimas de los conflictos armados. 
Asimismo, existen circunstancias en Colombia, como las descritas, que han significado un reconocimiento limitado, mediante actos unilaterales del Estado, que se han materializado a través de actos o acuerdos humanitarios o acuerdos de paz o, de manera general, cumpliendo el contenido de lo pactado, incorporándolo al orden nacional y con el respaldo y legitimización de actores internacionales. Todo lo anterior ha significado un avance sustancial en la tarea inaplazable y urgente de humanizar con apoyo externo el conflicto internacionalizado en Colombia. 


\section{Referencias}

Borda, S. (2007). La internacionalización del conflicto armado después del 11 de septiembre: ¿La ejecución de una estrategia diplomática hábil o la simple ocurrencia de lo inevitable? Colombia Internacional (65), 66-89.

Castro, J. (2013, 23 de agosto). ¿Conflicto internacionalizado? Ámbito Jurídico. https://www.ambitojuridico.com/noticias/educacion-y-cultura/ conflicto-internacionalizado

Comando Central del ELn. (2004, mayo). Agenda Nacional Alternativa: Una propuesta del Ejército de Liberación Nacional. https://www.aporrea.org/ actualidad/a8055.html

Comisión de Derecho Internacional. (2006). Principios rectores aplicables a las declaraciones unilaterales de los Estados. Naciones Unidas.

Comité Internacional de la Cruz Roja (CICR). (1984, 1 de enero). Introducción al derecho internacional humanitario. https://www.icrc.org/es/doc/ resources/documents/misc/5tdl7w.htm

Comité Internacional de la Cruz Roja (CICR). (2008). Comentario del Protocolo del 8 de junio de 1977 adicional a los Convenios de Ginebra del 12 de agosto de 1949-Protocolo I, tomo II. Autor.

Comité Internacional de la Cruz Roja (CICR). (2012, abril). Implementación del derecho internacional humanitario. https://www.icrc.org/es/doc/assets/ files/publications/icrc-002-4028.pdf

Coordinadora Guerrillera Simón Bolívar. (s. f.). Normas de comportamiento con las masas. http://www.pazfarc-ep.org/index.php/noticias-comunicadosdocumentos-farc-ep/delegacion-de-paz-farc-ep/2318-reflexion-3-larebelion-frente-a-la-paz-como-derecho-sintesis

Charry, J. M. (2008, 19 de enero). Estatus de beligerancia. El Tiempo. https:// www.eltiempo.com/archivo/documento/MAM-2798058

David, S. (1997). Internal war: Causes and cures. World Politics, 49(4), 552-576.

Decision on the Defence Motion for Jurisdiction. Prosecutor v. Tadic, Case n. ${ }^{\circ}$ IT-94-1-T (Appeals Chamber 2 de Octubre de 1995).

Embajada de Francia en El Salvador. (2016). xхXV Aniversario de la Declaración franco-mexicana. San Salvador. 
Galán, F., \& Torres, F. (1995). El Proceso de Paz: Resumen informativo interno n. ${ }^{\circ}$ 2. En Paz integral y diálogo útil. Oficina del Alto Comisionado para la Paz.

International Criminal Tribunal for the former Yugoslavia. (1997, mayo). Prosecutor versus Tadic. Case IT-94-1-T.

International Criminal Tribunal for Rwanda. (1998, 2 de septiembre). The Prosecutor versus Jean-Paul Akayesu, ICTR-96-4-T. Chamber I 2.

Kirk-Greene, A. H. (1971). Crisis and conflict in Nigeria: A documentary sourcebook. Oxford University Press.

Las Farc desestiman la mediación de la onU en el conflicto colombiano. (2002, 9 de agosto). El País. https://elpais.com/internacional/2002/08/10/actualidad/1028930402_850215.html

López Michelsen, A. (2008). ¿Cómo desempantanar el acuerdo humanitario? El Áncora.

Los diez países amigos regresan al área neutral de Colombia. (2002, 17 de enero). El País. https://elpais.com/internacional/2002/01/18/actualidad/1011308406_850215.html

Medina, C. (2012). Ejército de Liberación Nacional: Notas para una historia de las ideas políticas. Universidad Nacional de Colombia.

Méndez, A. (2017). Colombian Agency and the Making of US Foreign Policy: Intervention by invitation. Routledge.

Pacheco Sánchez, R. (2013). Reconocimiento de beligerancias. http://www. unilibrebaq.edu.co/unilibrebaq/pdhulbq/publicaciones/reconocimientobeligerancias.pdf

Pardo, R., \& Carvajal, L. (2003). La internacionalización del conflicto doméstico y procesos de paz. En Desafíos y prioridades de la política exterior colombiana (pp. 181-236). Fescol.

Pastrana, A. (1999). Hechos de paz: A la mesa de negociación. Presidencia de la República de Colombia.

Peace Agreements. (2001, 24 de noviembre). Acuerdo por Colombia entre el Gobierno Colombiano y el Ejército de Liberación Nacional (ELN): Reiniciar el diálogo con una agenda de transición. https://www.peaceagreements.org/search?SearchForm\%5Bregion\%5D=2\&SearchF orm $\% 5$ Bcountry_entity $\% 5 \mathrm{D}=32 \&$ SearchForm $\% 5$ Bname $\% 5 \mathrm{D}=\& \mathrm{~S}$ earchForm $\% 5$ Bcategory_mode $\% 5 \mathrm{D}=$ all $\&$ SearchForm $\% 5$ Bagreeme nt_text $\% 5 \mathrm{D}=\mathrm{ELN} \& \mathrm{~s}=$ Search+Database 
Pizarro Leongómez, E. (2011, 9 de mayo). Las Farc y el reconocimiento de beligerancia. El Tiempo. https://www.eltiempo.com/archivo/documento/ CMS-9318340

Quintana, J. J. (2001). Derecho internacional público contemporáneo. Ediciones Jurídicas Gustavo Ibáñez.

Rangel, A. (1995, 18 de junio). Beligerancia y humanización. El Tiempo. https://www.eltiempo.com/archivo/documento/MAM-347174

Sánchez Patrón, J. M. (2006). El ámbito de aplicación del derecho internacional humanitario. Agenda Internacional (23), 57-91.

Stewart, J. G. (2003). Towards a single definition of armed conflict in international humanitarian law: A critique of internationalized armed conflicts. International Review of the Red Cross, 85(850), 313-350. http://www.icrc. org/Web/eng/siteeng0.nsf/htmlall/5PYAXX/\$File/irrc_850_Stewart.pdf

Tickner, A. (2007). Intervención por invitación: Claves de la política exterior colombiana y sus debilidades. Colombia Internacional (65), 90-111.

Torres Rivas, E. (2002). La democracia como estrategia contrainsurgente. En Especial Radio Nederland XX Aniversario de Esquipulas.

United Nations. (2008). Int'l law comm'n, draft articles on responsibility of states for internationally wrongful acts. International Law Commission. Valencia Tovar, A. (1995, 23 de junio). Beligerancia y humanización. El Tiempo. https://www.eltiempo.com/archivo/documento/мam-351037

Valencia Tovar, A. (1999, 22 de octubre). El estatus de beligerancia. El Tiempo. https://www.eltiempo.com/archivo/documento/мaм-956171 